\title{
Short-term stability of single motor unit recordings in motor neuron disease: a macro EMG study
}

\author{
R J GUILOFF, H MODARRES-SADEGHI, E STÅLBERG, * H ROGERS \\ From the Department of Neurology, Westminster Hospital, Charing Cross and Westminster Medical School, \\ London, UK
}

SUMMARY Thirty five individual macro EMG motor unit potentials in 13 patients with motor neuron disease were recorded every 15 minutes during a 2 hour period. No significant change in amplitude or area was seen in 15 control units in nine patients or in 20 units in 11 patients receiving RX77368 $0 \cdot 2-0 \cdot 3 \mathrm{mg} / \mathrm{kg}$. The findings provide no evidence for an action of this long acting TRH analogue on the peripheral territory of motor units in motor neuron disease.

There is evidence that high dose thyrotropin releasing hormone (TRH) and an analogue with a dimethyl substitution in the prolineamide end of the molecule ( $\mathrm{RX77368)}$ can produce temporary change in muscle force, increase in fasciculations, decrease in spasticity and improvement in certain parameters of bulbar function in patients with motor neuron disease. ${ }^{12}$

The mechanisms mediating such pharmacological actions are unknown. TRH and analogues have an excitatory action on anterior horn cells in the frog, ${ }^{34}$ toad, ${ }^{5}$ rat $^{6-9}$ and cat. ${ }^{10} \mathrm{~F}$ and $\mathrm{H}$ wave studies in man suggest an action of native TRH in spinal interneurons. ${ }^{11}{ }^{12}$ In previous studies ${ }^{13}$ in motor neuron disease, RX77368 produced an acute 25-30\% increase in mean corrected fibre density (FD-1) and in mean Macro EMG (MAC) median amplitude and area in brachial biceps muscle. The drug produced no significant change in the mean percentage of individual MAC potentials with amplitude or area above the upper limit of normal. ${ }^{13}$ There was no change in the mean amplitude of the compound muscle action potential (MAP) of biceps obtained by stimulation at Erbs point. Repetitive stimulation showed no significant decrement in the MAP response of abductor digiti minimi. The findings were interpreted as consistent with a "central", direct or indirect, action of RX77368 on anterior horn cells. They suggested a change in recruitment order and/or in activa-

Address for reprint requests: Dr $\mathbf{R} \mathbf{J}$ Guiloff, Department of Neurology, Westminster Hospital, 17 Page Street, London SW1P 2AP, UK.

*Address: Department of Clinical Neurophysiology, Uppsala University, Sweden.

Received 21 August 1987 and in revised form 8 December 1987. Accepted 15 December 1987 tion threshold of pathological motor units.

If the observed changes in MAC and FD with RX77368 are not accounted for by a change in the functional peripheral territory of individual motor units it would be expected that no significant change in MAC amplitude and area would occur in such single motor units followed during the period of drug infusion.

We report the results obtained in 35 single motor units followed with the MAC technique for 2 hours during or without infusion of RX77368.

\section{Material and methods}

Thirteen patients with motor neuron disease participated. Eleven received L-pyroglutamyl L hystidyl L-3,3 dimethylprolineamide (RX77368) over 2 hours. Seven of them also had control recordings at least 7 days after or before drug infusion. Two further patients had control recordings but did not receive the drug. Age, sex, clinical form, duration of illness, type and number of motor units recorded, muscle tested and its force, presence of increased fasciculations and clinical shivering with drug infusion and dose are summarised in table 1 .

Recordings were performed with a Neuromatic $2000 \mathrm{M}$ EMG machine (Dantec). Dantec electrodes were used: concentric needle (13L50) and macro EMG (13K88). Filter settings for fibre density (FD) were $500 \mathrm{~Hz}-10 \mathrm{~Hz}$ and for Macro EMG (MAC) $10 \mathrm{~Hz}-10 \mathrm{KHz}$. MAC of brachial biceps, vastus lateralis and tibialis anterior muscles was recorded with the technique described by Stålberg. ${ }^{1415}$ The remote electrode was placed subcutaneously over the head of the radius for biceps, and in the lateral aspect of the knee above the head of the fibula for tibialis anterior and vastus lateralis. Measurements of MAC signal amplitude and area were computer aided (6502 microprocessor, SES software). The areas of six units which could not be measured by this method were excluded. All MAC potentials were recorded 
Table 1 Patients and motor units

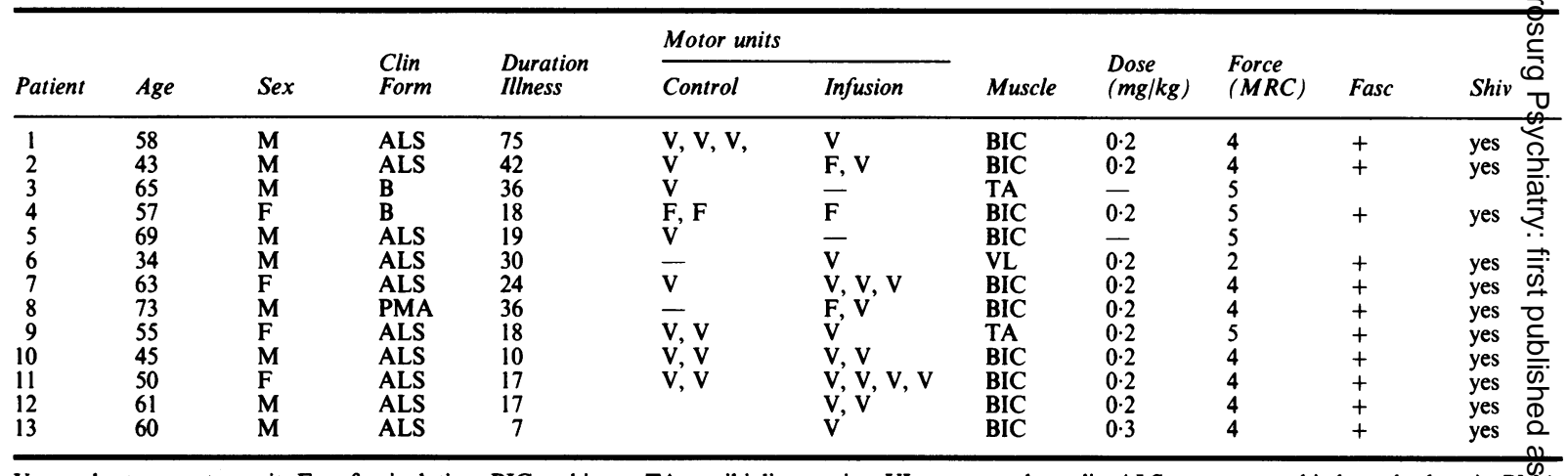

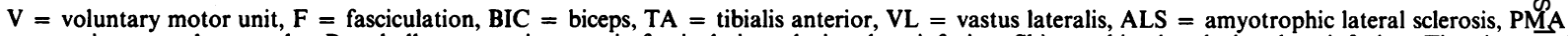

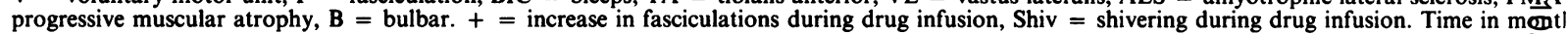

Table 2 Features of MACRO EMG motor unit potentials during baseline recordings

\begin{tabular}{|c|c|c|c|c|c|}
\hline & \multirow{2}{*}{$\begin{array}{l}\text { Mean amplitude } \\
(\mu V)\end{array}$} & \multirow{2}{*}{$\begin{array}{l}\text { Mean area, } \\
(\mu V \times m s)\end{array}$} & \multicolumn{2}{|c|}{ Number above normal limit* } & \multirow{2}{*}{$\begin{array}{l}\text { Mean number of } \\
\text { SFP }\end{array}$} \\
\hline & & & Units & Patients & \\
\hline $\begin{array}{l}\text { All units } \\
\text { Control units } \\
\text { Drug units }\end{array}$ & $\begin{array}{l}963 \cdot 6, \text { SE } 140 \cdot 9(35) \\
937 \cdot 7 \text {, SE } 186 \cdot 2(15) \\
983 \cdot 0 \text {, SE } 207 \cdot 1(20)\end{array}$ & $\begin{array}{l}3880 \text {, SE } 519(29) \\
3535 \text {, SE } 683(13) \\
4161, \text { SE } 773(16)\end{array}$ & $\begin{array}{l}21 \\
10 \\
11\end{array}$ & $\begin{array}{r}10 \\
8 \\
9\end{array}$ & $\begin{array}{l}2.9, \text { SE } 0.3(26) \\
3 \cdot 1 \text {, SE } 0.6(10) \\
2 \cdot 8, \text { SE } 0.3(16)\end{array}$ \\
\hline
\end{tabular}

*For individual MACRO potentials (15); SFP: Number of spikes in the triggering single fibre potential during MAC motor unit recordings Numbers in brackets indicate number of motor units for which information was available.

on paper. Where comparisons with normal values for MAC are made, those published elsewhere have been used. ${ }^{15}$ Fibre density criteria were $0.2 \mathrm{mV}$ or more in amplitude, $300 \mathrm{~ms}$ or less in duration. ${ }^{16}$ The number of spikes in the triggering single fibre signal for each single motor unit during MAC recordings was visually counted and followed up in 26 of the 35 units studied. The skin temperature over the muscle tested was kept constant at $32^{\circ} \mathrm{C}$ with radiant heat.

A unit was accepted as soon as a randomly found single fibre signal could be kept on the screen for analysis. An optimal position for the MAC electrode was then found for each motor unit by monitoring the single fibre signal, independent of the MAC potential. The lead was secured to the skin with adhesive tape and the electrode was then left in the same place for the rest of the recording session. Occasionally a minor adjustment of its position was made. The patient was asked to activate periodically the motor units by slight voluntary contraction until an average potential of 50 to 200 discharges was obtained and measured and to rest in between recordings. For fasciculations $(n=5$, table 1$)$ the amplitude and area of a single potential was measured at each sampling point since there was no other background activity. The amplitude of the fasciculation potentials did not exceed the average of the voluntarily activated units and therefore each of them seem to represent only one motor unit. The stability in amplitude, area and shape throughout the recordings of such recurrent fasciculations indicate that the same motor unit was activated. For each unit a baseline mean amplitude and area, with standard error were obtained by performing three to 10 recordings over periods from 5 to 45 minutes (fig 1). Subsequently recordings of the same unit were made every 15 minutes over 2 hours with drug infusion or without (control units) (fig 3).

It was not possible to record all units throughout the 2 hours due to loss of the single fibre triggering potential. The number of units available at each temporal sampling point is given in fig 4 . At the end of 2 hours 13 of 20 drug units $(65 \%)$ and 11 of 15 control units $(73 \%)$ could still be recorded. This difference is not statistically significant (chi-square $=0.024$, d.f. $=1, p=0.87$, with Yates correction) suggesting that drug administration, including associated shivering, was not relevant in this respect.

For analysis of results MAC amplitude and area of each motor unit over the 2 hour recordings were expressed as percentage of its own baseline mean. To obtain mean and SE of amplitude and area of all units available at each sampling point during the 2 hour recordings these percentage values were taken. By expressing the standard error of each motor units baseline mean as a percentage, a mean percentage standard error of all baseline means $(n=35)$ was obtained (fig 4).

An analysis of variance was used for statistical comparisons or control and drug units at each temporal sampling point.

All patients gave written informed consent. The study was approved by the local Ethical Committee. 


\section{Results}

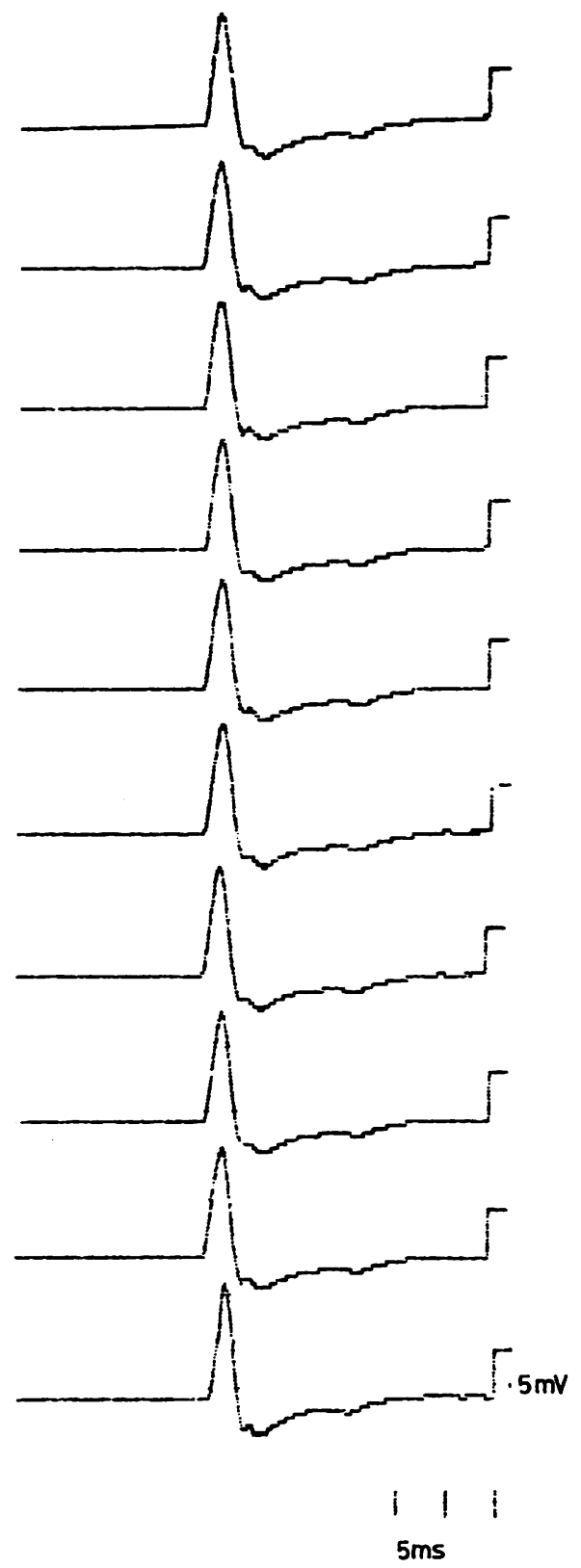

Fig 1 Example of 10 successive baseline recordings of one voluntarily activated Macro EMG motor unit in brachial biceps recorded over 14 minutes. Each potential is the average of 50-200 discharges. The unit was only activated during each recording, that is, 10 times. See also fig 4.
The baseline mean values for MAC amplitude and area for control motor units and for those followed during drug infusion were very close. The number of baseline MAC motor units with amplitude above the normal limit and the number of patients in whom they were recorded were both also similar in the control and drug groups (table 2).

The mean percentage standard error of the baselines for all motor units was $2 \cdot 15 \%(n=35$; $\min 0 \cdot 58$, $\max 7.84)$ for MAC amplitude and $2.48 \%(n=29$; $\min 0.25$, max 5.95) for MAC area (fig 4).

The amplitude of all MAC potentials during 2 hour recordings fell within $99 \%$ confidence limits of mean baseline values, both for control motor units $(96$ potentials) and drug motor units (133 potentials). The same was true for area of all control MAC potentials $(n=84)$. Only one of 102 areas of MAC potentials during drug infusion fell outside this limit but was inside $95 \%$ confidence limits of mean baseline.

Figure 2 shows the normal distribution of MAC amplitude and area of all potentials during 2 hour recordings. An analysis of variance showed no significant difference between drug and control motor units either for MAC amplitude $(\mathrm{df}=7 ; \mathrm{F}$ ratio $=$ $1.11 ; \mathrm{p}=0.35)$ or area $(\mathrm{df}=7 ; \mathrm{F}$ ratio $=1.30 ; \mathrm{p}=$ 0.25 ) at any of the eight sampling points during the 2 hour recordings.

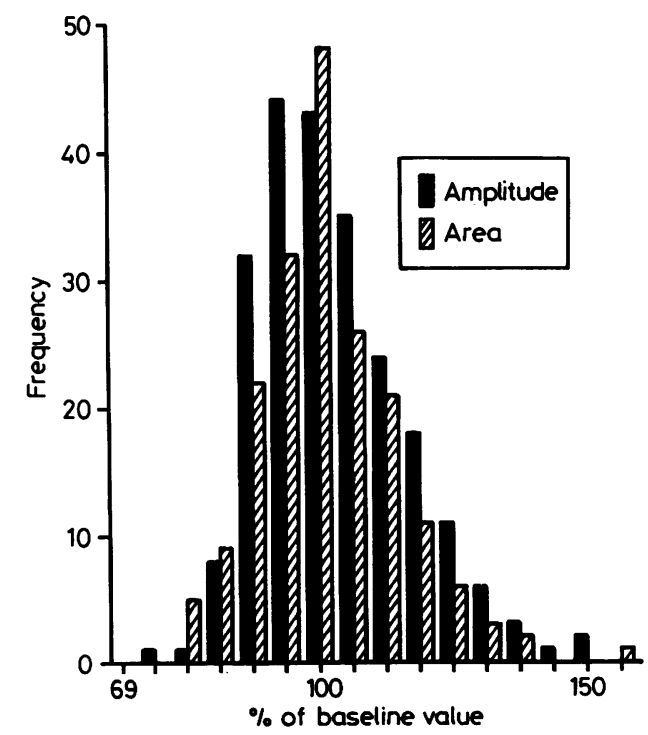

Fig 2 Frequency distribution of amplitude and area of all Macro EMG potentials as percentage of baseline value during 2 hour control and drug infusion recordings. 


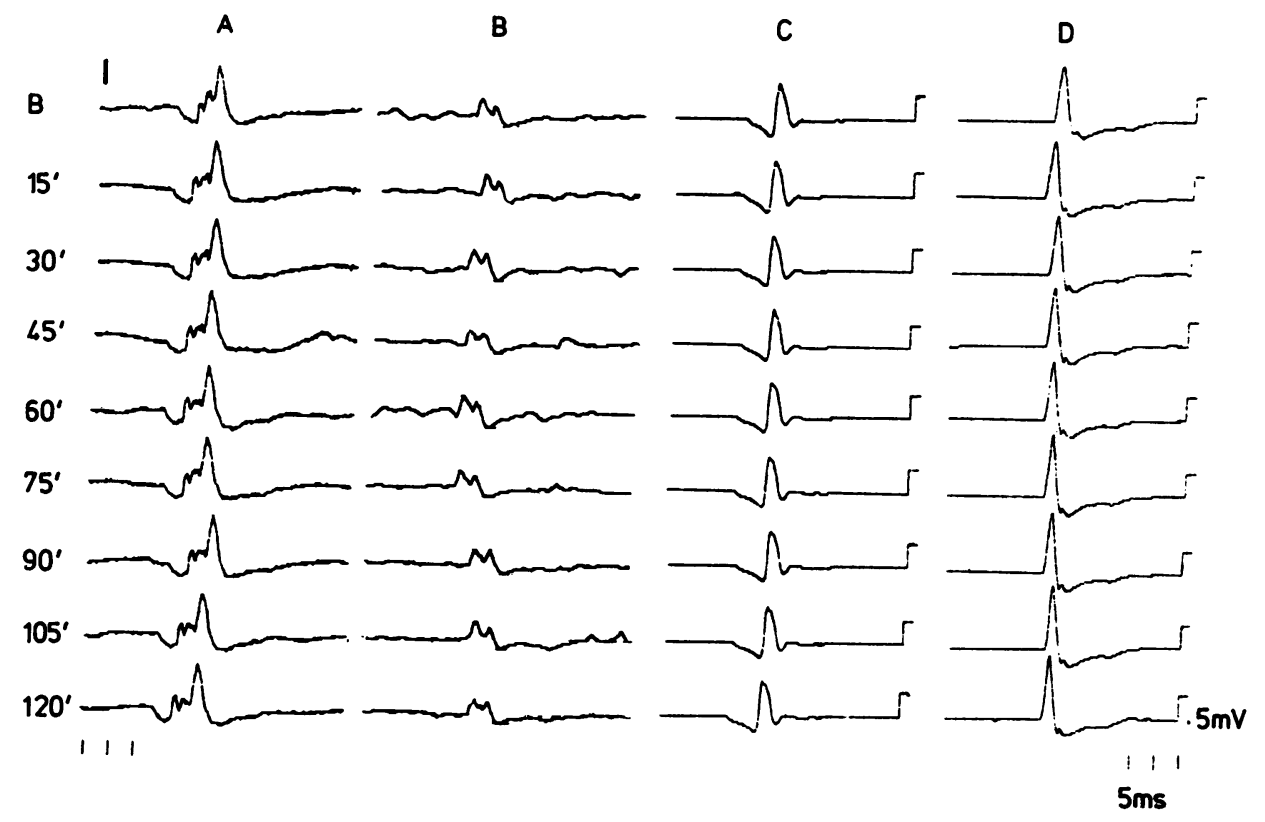

Fig 3 Examples of Macro EMG motor units in four patients during 2 hour recordings. Each voluntary motor unit was activated only every $15 \mathrm{~min}$ and each potential is the average of 50-200 discharges. Each fasciculation potential is a single discharge. $B=$ example of baseline for each motor unit. Sampling times are indicated. $A=$ Fasciculation in biceps, control; $B=$ Fasciculation in biceps during drug infusion. $C=$ Voluntary motor unit in tibialis anterior, control. $D=$ Voluntary motor unit in biceps during drug infusion (ten baseline potentials for this unit are shown in fig 1). RX77368 $0 \cdot 2 \mathrm{mg} / \mathrm{kg}$.

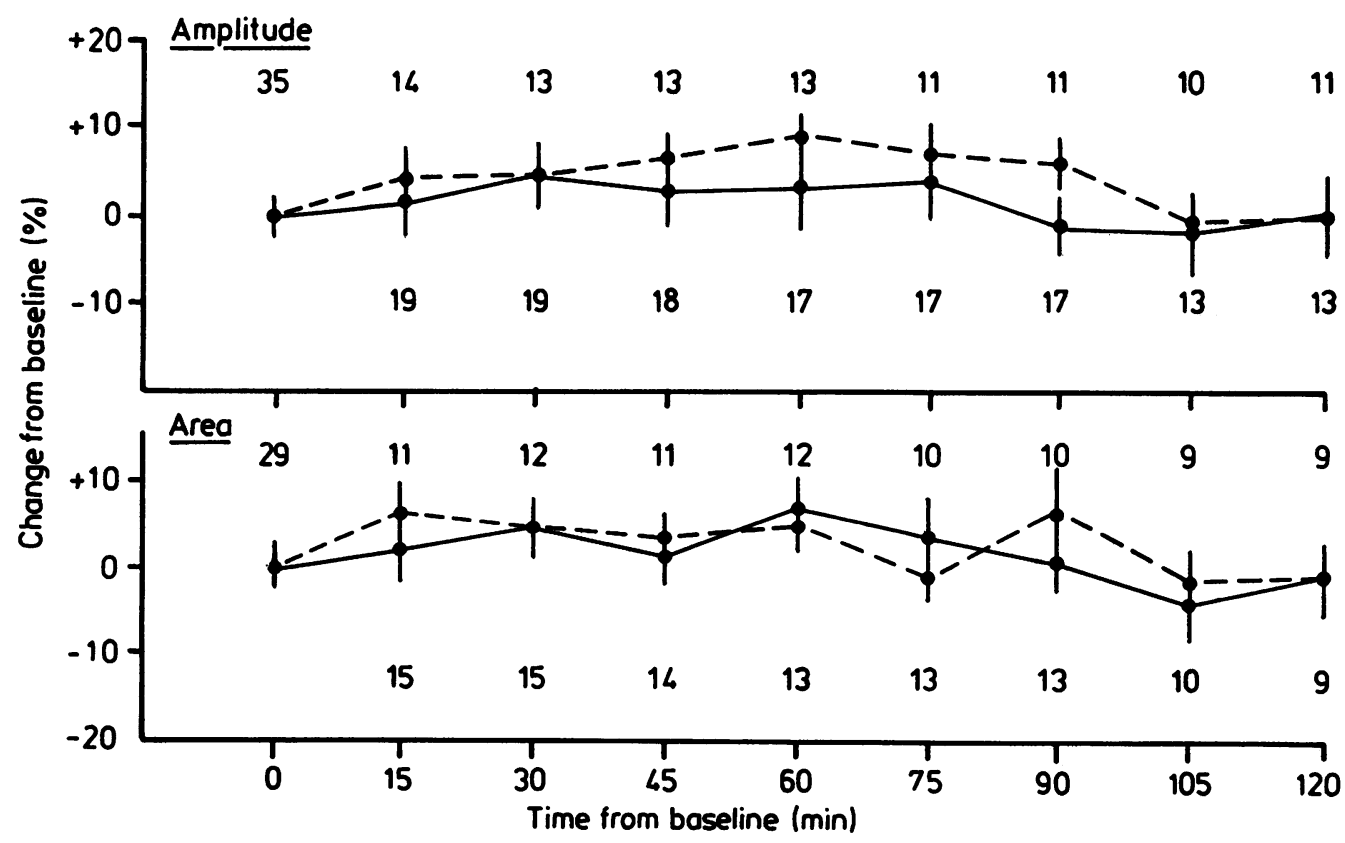

Fig 4 Time course of changes in Macro EMG amplitude (above) and area (below) during 2 hour recordings for all control and drug units. Values plotted at sampling points every 15 minutes are the mean, and SE for these units expressed as percentage of their baseline. Broken line = control; Full line $=$ drug. The number of units available at each sampling point is indicated by the numbers above (control) and below (drug) the lines in each graph. Drug = $R X 77368$. 
Figure 3 shows individual examples of MAC motor units during control and drug infusion recordings. Figure 4 shows no significant change from baseline nor between drug and control groups in MAC amplitude and area at each of the eight sampling points over 2 hour recordings.

The mean number of single fibre potentials during MAC recordings was not significantly different in drug and control units (table 2). No change was observed in the number of single muscle fibres detected with the single fibre electrode during MAC recordings.

All patients receiving $\mathrm{RX} 77368$ had clinical increase in fasciculations and shivering in the second hour of infusion.

\section{Discussion}

The MAC shape, amplitude and area of single voluntarily activated motor units and fasciculation potentials were remarkably stable both during baseline measurements and during 2 hour control and TRH analogue infusion recordings. The populations of motor units recorded during control and drug infusions were comparable.

A mean $25-30 \%$ increase in mean corrected FD (FD-1) and in mean MAC median amplitude and area in brachial biceps, in the last $30 \mathrm{~min}$ of a 2 hour iv infusion of RX77368 has been found previously. ${ }^{13}$ If this change was related to an effect on the peripheral territory of the motor units (terminal axons/end plates/muscle fibres) then an increase in MAC amplitude and area of individual motor units should be found. Taking the limits, this mean increase could be the result of a $25-30 \%$ change in all motor units sampled or to large increases in amplitude in a few units. If the drug modified the functional territory of only $20 \%$ of the sampled motor units then a mean $250 \%$ increase in amplitude in one fifth of the motor units would be required to account for the mean increase in MAC and FD previously found.

All values for MAC amplitude and area in this study fell within $99 \%$ confidence limits of mean baseline values (except for one area value which fell within $\mathbf{9 5 \%}$ confidence limits). Further, no change in the number of single fibre potentials recorded for each motor unit was observed. Two hour recordings showed no difference between drug and control units in amplitude or area at any of the recordings performed every 15 minutes. This included one patient (case 1) who had participated in our electrophysiological study ${ }^{13}$ and had shown a $50 \%$ increase in corrected fibre density and $24 \%$ and $49 \%$ increases in Macro EMG median amplitude and area respectively (table 1 , case 3$).{ }^{13}$

The dose given was smaller $(0.2 \mathrm{mg} / \mathrm{kg})$ than in the previous study $(0.3 \mathrm{mg} / \mathrm{kg})^{13}$ in 10 of the patients because of the need to reduce side effects. The clinical effects, however, including increase in fasciculations, change in muscle force and shivering were comparable with $0 \cdot 2$ and $0 \cdot 3 \mathrm{mg} / \mathrm{kg}^{2}{ }^{17}$

The findings of this study support the previous hypothesis that the acute action of RX77368 on MAC and FD parameters is the result of a direct or indirect "central" effect of this analogue on motor neurons. ${ }^{13}$

We are grateful to the following physicians for referring patients: C Evans, C Hawkes, J Jestico, R McKeran, A Turner, S Wilson.

This work was supported by the Motorneuron Disease Association of Great Britain, The North West Thames Regional Health Authority, The Special Trustees of Westminster and Roehampton Hospitals and the Mason Medical Research Foundation.

\section{References}

1 Engel WK, Siddique T, Nicoloff JT. Effect of weakness and spasticity in amyotrophic lateral sclerosis of thyrotropin releasing hormone. Lancet 1983;2:73-5.

2 Guiloff RJ, Eckland DJA, Demain C et al. Controlled acute trial of a thyrotropin releasing hormone analogue (RX77638) in motor neuron disease. $J$ Neurol Neurosurg Psychiatry 1987;50:1359-70.

3 Nicoll RA. Excitatory action of TRH on spinal motorneurons. Nature 1977;265:242-3.

4 Nicoll RA. The action of thyrotropin-releasing hormone substance $P$ and related peptides on frog spinal motorneurones. J Pharmacol Exp Ther 1978;207:817-24.

5 Phillis JW, Kirkpatrick JR. Actions of various gastro intestinal peptides on the isolated amphibian spinal cord. Can J Physiol Pharmacol 1979;57:887-99.

6 Ono H, Fukuda H. Ventral root depolarisation and spinal reflex augmentation by a TRH analogue in rat spinal cord. Neuropharmacology 1982;21:739-44.

7 Pawlowski L, Ruszynska J, Przegalinski E. The effect of thyroliberin and some of its analogues on the hind limb flexor reflex in the spinal rat. Pol J Pharmacol Pharm 1980;32:539-50.

8 Clarke KA, Stirk G. Motorneuron excitability after administration of a thyrotropin-releasing hormone analogue. Br J Pharmacol 1983;80:561-2.

9 Clarke KA, Parker AJ, Stirk GC. Motor neuron excitability during antidromically evoked inhibition after administration of a thyrotropin-releasing (TRH) analogue. Neuropeptides 1984;4:403-11.

10 Cooper BR, Boyer CE. Stimulant action of thyrotropin releasing hormone on cat spinal cord. Neuropharmacology 1978;17:153-6.

11 Delwaide PJ, Schoener J. The effects of TRH on F waves recorded from antagonistic muscles in human subjects. Ann Neurol 1985;18:366-7.

12 Pierrot-Deseilligny, Engel WK, Fardeau M. Effect of high dose TRH (HD-TRH) on H-reflex vibratory 
inhibition and $\mathrm{H}$-reflex threshold in amyotrophic lateral sclerosis (ALS) patients. Neurology 1985;35 (Suppl 1): 106

13 Guiloff RJ, Stålberg E, Eckland DJA, et al. Electrophysiological observations in patients with motor neuron disease receiving a TRH analogue (RX77368). J Neurol Neurosurg Psychiatry 1987;50:1633-40.

14 Stålberg E. Macro EMG, a new recording technique. $J$ Neurol Neurosurg Psychiatry 1980;43:475-82.
15 Stålberg E, Fawcett PRW. Macro EMG in healthy subjects of different ages. $J$ Neurol Neurosurg Psychiatry 1982;45:870-8.

16 Stålberg E, Trontelji J. Single Fibre Electromyography, Surrey. The Mirvalle Press Ltd, UK 1979.

17 Modarres-Sadeghi H, Guiloff RJ. Subacute administration of a TRH analogue (RX77368) in motor neuron disease: an open study. $J$ Neurol Neurosurg Psychiatry (in press).

\section{The thalamic syndrome of Dejerine and Roussy}

In a series of publications between 1903 and 1907, Dejerine and Roussy provided the earliest formal accounts of "Le syndrome thalamique". The better known of these names conjures up a legacy of classic eponymous syndromes: facioscapulo-humeral dystrophy (Landouzy-Dejerine); hypertrophic interstitial polyneuritis (Dejerine-Sottas); olivo-ponto-cerebellar atrophy (Dejerine \& Andre-Thomas). Dejerine also described: alexia without agraphia (pure alexia) and alexia with agraphia.

The precipitation of root pain by sneezing and coughing should also be referred to as Dejerine's sign; he popularised it in a 1905 paper and in his later text Traité des maladies de la moelle épinière, 1909.

Jules Dejerine was born in Geneva in 1849 , graduated in medicine in Paris in 1879 and followed Raymond in the chair held by Charcot at Salpêtrière. He married Augusta Klumpke who in 1885 left for posterity Contributions a l'étude des paralysies radiculaires du plexus brachial. He was elected to the Academy of Medicine in 1908 and died on February 26th 1917.

The 1906 paper $^{1}$ in translation" described "a syndrome characterised by:

"1. A slight hemiplegia, usually without contracture and rapidly regressive.

2. A persistent superficial hemianaesthesia of an organic character, which can in some cases be replaced by cutaneous hyperaesthesia but is always accompanied by marked and persistent disturbances of deep sensation.

3. Mild hemiataxia and more or less complete astereognosis.

4. Severe, persistent, paroxysmal and often intolerable pains on the hemiplegic side, not yielding to any analgesic treatment.

5. Choreoathetoid movements in the limbs on the paralyzed side."

This definition was followed by a "Clinical Study" elaborating the salient features, emphasising the mildness of the hemiplegia, its improvement, but noting "the sensory phenomena usually persist until death. The symptoms of the thalamic syndrome appear a few months or even better a year after the hemiplegia... the chorea is not a major hemichorea ... but small movements... in the fingers and hand.' The hemiataxia "is slight, apparently not connected with the intensity of sensory disturbances... an uneasiness, a certain hesitation... Reflexes sometimes slightly exaggerated; sometimes almost normal. The cutaneous reflexes and the plantar reflex are normal or absent. The absence of the
Babinski response in all our cases, despite the pyramidal degeneration ... deserves mention."

"Sensory disorders... dominate the symptomatology. (a) Objective sensation-superficial, involving touch, pain and temperature, never absolute, predominates distally, and on the trunk and face goes slightly over the midline 1 to $2 \mathrm{~cm}$. Deep sensation is affected much more ... osseous sensitivity, complete loss of muscle sense, ... sensation of weight ... position sense ... "stereognosis" is always affected." (b) Subjective sensation-pain on the hemiplegic side "of central origin", dating from the onset or a few months later... pains continuous, with paroxysmal exacerbations, bringing cries from the patient, keeping them from sleep ... provoked by touching, pinprick, contact with cold and heat and pressure... not suppressed by analgesic treatment... suffering is sometimes intolerable."

The pathological anatomy was based on three specimens. They concluded "when the lesion occupies the external nucleus (external and posterior part) extending through the internal and median nuclei of the thalamus, involving only a part of the fibres of the posterior limb of the internal capsule, the clinical picture of the thalamic syndrome results."

It was in 1923 that Foix and Masson showed the most common cause was "Le syndrome de l'artère cérébrale posterieure". ${ }^{3}$

\section{References}

JMS PEARCE

1 Dejerine J, Roussy G. Le syndrome thalamique. Rev Neurol (Paris) 1906;14:521-32.

2 Wilkins RH, Brody IA. The thalamic syndrome. Arch Neurol 1969;20:559-62.

3 Foix C, Masson A. Le syndrome de l'artère cérébrale posterieure. Presse Med 1923;31:361-65.

\section{Huntington's chorea}

"It is as common and is indeed, I believe, more common among men than women, while I am not aware that season or complexion has any influence in the matter. There are three marked peculiarities in this disease: (1) Its hereditary nature. (2) A tendency to insanity and suicide. (3) Its manifesting itself as a grave disease only in adult life".

Huntington George. On Chorea, The Medical and Surgical Reporter $1872 ; 26: 317-321$

RT ROSS 